\title{
Review \\ A Comparison of the Effect of Strength Training on Cycling Performance between Men and Women
}

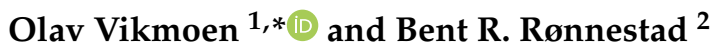 \\ 1 Department of Physical Performance, Norwegian School of Sport Sciences, 0806 Oslo, Norway \\ 2 Section for Health and Exercise Physiology, Institute of Public Health and Sport Sciences, Inland Norway \\ University of Applied Sciences, 2418 Elverum, Norway; bent.ronnestad@inn.no \\ * Correspondence: olavv@nih.no
}

check for

updates

Citation: Vikmoen, O.; Rønnestad, B.R. A Comparison of the Effect of Strength Training on Cycling Performance between Men and Women. J. Funct. Morphol. Kinesiol. 2021, 6, 29. https://doi.org/ 10.3390/jfmk6010029

Received: 26 February 2021

Accepted: 15 March 2021

Published: 17 March 2021

Publisher's Note: MDPI stays neutral with regard to jurisdictional claims in published maps and institutional affiliations.

Copyright: (C) 2021 by the authors. Licensee MDPI, Basel, Switzerland. This article is an open access article distributed under the terms and conditions of the Creative Commons Attribution (CC BY) license (https:// creativecommons.org/licenses/by/ $4.0 /)$.

\begin{abstract}
During the last decade numerous review articles have been published on how concurrent strength and endurance training affect cycling performance. However, none of these have reviewed if there are any sex differences in the effects of concurrent training on cycling performance, and most research in this area has been performed with male cyclists. Thus, the aim of the current paper is to review the scientific literature on the effect of concurrent training on cycling performance in male and female cyclists with a special emphasis on potential sex differences. The results indicate that both male and female cyclists experience a similar beneficial effect from concurrent training on cycling performance and its physiological determinants compared to normal endurance training only. Some data indicate that women have a larger effect on cycling economy, but more studies are needed to explore this further. Furthermore, the adaptations to strength training thought to be responsible for the beneficial effects on cycling performance seem to be very similar between men and women. Interestingly, increased muscle cross-sectional area in the main locomotor muscles seems to be an important adaptation for improved performance, and, contrary to popular belief, cyclists should aim for increased muscle cross-sectional area when adding strength training to their normal training. We conclude that both male and female cyclists can improve their cycling performance by adding strength training to their normal training.
\end{abstract}

Keywords: concurrent training; endurance performance; sex differences; muscle strength; muscle hypertrophy; training adaptations

\section{Introduction}

Adding strength training to cyclists normal training has been shown to improve cycling performance [1-3], and during the last decade there has been published numerous review articles on the effects of strength training on cycling performance [4-6]. However, none of these have reviewed whether there are any sex differences regarding the effects of strength training on cycling performance. In fact, the literature investigating the effects of adding strength training to the usual training in cyclists is dominated by studies performed on male cyclists. One of the few studies investigating the effect of adding strength training to the usual training of female cyclists reported no beneficial effect on cycling performance in a $1 \mathrm{~h}$ time-trial test nor in cycling economy [7]. However, the cyclists in this study performed only one strength training exercise (parallel squats), and this was probably not a sufficient training volume for beneficial effects to occur [8]. A recent study reported improved average power output during and 8-min performance test in trained female cyclists after 6 weeks of either traditional or velocity-based strength training [9]. However, this study did not include a control group only performing endurance training, making it difficult to assess if the improved performance was because of the strength training per se. Furthermore, to the best of our knowledge, no study has directly compared the effects between men and women in one single study. There are some physiological differences between men and women that in theory might lead to different effects of strength training 
on cycling performance. For example, when performing muscle contractions at the same relative intensities, women have been reported to be more resistant to muscle fatigue [10], and during endurance exercise at submaximal intensities, women oxidize proportionally more fat and less carbohydrate and protein than men [11]. Furthermore, endocrine responses differ between men and women in response to exercise [12,13], and the adaptations in the mechanical properties of tendons after strength training are different [14]. Some years ago, we conducted a more thorough investigation on the effects of strength training on cycling performance and performance determinants in female cyclists $[2,15]$. This study utilized a strength training program, a testing regime, and testing equipment identical to what we used in male cyclists with beneficial effects on cycling performance $[1,16,17]$, making these studies very suitable for comparing the effects between male and female cyclists. To the best of our knowledge, this study is the only study using a strength training program with a sufficient volume and training load to investigate if female cyclists can benefit from strength training.

In the current review, we first present a short summary of the effects of adding strength training to cyclists' normal training regimes regarding cycling performance and performance determinants regardless of sex. Thereafter, we compare these effects between male and female cyclists with an emphasis on our own studies using a similar training program and testing protocol in both male and female cyclists. Finally, we include a review of the adaptations to strength training thought to induce beneficial effects on cycling performance and discuss if these might be different between men and women.

\section{The Effects of Strength Training on Cycling Performance and Its Physiological Determinants}

Cycling performance is determined by several physiological performance determinants. The interaction between maximal oxygen consumption $\left(\mathrm{VO}_{2 \max }\right)$ and fractional utilization of $\mathrm{VO}_{2 \max }\left(\% \mathrm{VO}_{2 \max }\right)$ determines the performance $\mathrm{VO}_{2}$, the rate of aerobic metabolism that can be sustained for the duration of a performance test or competition [18]. The cycling economy or efficiency then determines the power output at a given amount of energy consumption, and these three factors therefore majorly determine the average power output that can be sustained for a certain period of time or distance, a surrogate measure for cycling performance [18]. In the lab, cycling performance is often measured as the average maximal sustainable power output during 20-60 min tests.

Multiple studies reported improved cycling performance measured by this methodological approach after cyclists added heavy strength training (multiple leg exercises with $\sim 4-12$ repetitions maximum, for minimum 8 weeks) to their normal training $[2,17,19,20]$. In contrast, studies that included strength training programs of either short duration, included a low volume of strength training, or used explosive strength training [7,21-23] failed to show improved performance. Since combining heavy strength training with normal endurance training seems to improve cycling performance, it should also improve at least one of the cycling performance determinants. It seems to have neither a positive nor a negative effect on the development of $\mathrm{VO}_{2 \max }[2,7,22,24]$. When it comes to efficiency or cycling economy, the findings are more equivocal. When cycling economy is measured by the traditional method (i.e., short, 3-5 min, submaximal bouts of cycling), no additive effect of strength training has been observed in well-trained and elite cyclists $[1,3,17,25]$. However, improvements have been shown in moderate trained cyclists [24,26,27]. Interestingly, there are indications that heavy strength training improves cycling economy after prolonged submaximal cycling, also in well-trained cyclists, which is especially relevant in road cycling [16].

$\% \mathrm{VO}_{2 \max }$ is ideally measured directly via $\mathrm{VO}_{2}$ measurements during a performance test and then expressed as the average $\mathrm{VO}_{2}$ during the exercise in percent of $\mathrm{VO}_{2 \max }$. Only one study on the effects of strength training on cycling performance has measured $\% \mathrm{VO}_{2 \max }$ in this way and reported an improvement after strength training [2]. However, a common way to estimate $\% \mathrm{VO}_{2 \max }$ is to use the percentage of $\mathrm{VO}_{2 \max }$ at the lactate threshold, and the few studies that have reported the effect of concurrent training on this 
measurement in cyclists observed no change $[2,17,24]$. However, these data should be taken with caution as the only study reporting improved $\% \mathrm{VO}_{2 \max }$ mentioned above did not find a similar effect of strength training on lactate threshold expressed as percent of $\mathrm{VO}_{2 \max }$ [2]. Furthermore, other studies report improved performance without a concomitant improvement in $\mathrm{VO}_{2 \max }$ or cycling economy [1,3] after concurrent training, further supporting the claim that improved $\% \mathrm{VO}_{2 \max }$ can occur after concurrent training. The absolute power output at the lactate threshold is, amongst others, affected by the cycling economy. Therefore, and despite not all studies reporting significant improvement in cycling economy, the finding of improved lactate threshold power output in several studies after combined heavy strength- and endurance training is somewhat expected [1,2,17,20,25]. However, there are also studies observing no improvements in power output at a defined $\left[\mathrm{la}^{-}\right][3,23,24]$.

Another lab measurement that can be interpreted as a performance measurement is the peak minute power output achieved during an incremental cycling test to exhaustion when testing $\mathrm{VO}_{2 \max }\left(\mathrm{W}_{\max }\right)$. $\mathrm{W}_{\max }$ is influenced by $\mathrm{VO}_{2 \max }$, cycling economy, anaerobic capacity, and neuromuscular characteristics [28]. Accordingly, $W_{\max }$ has been shown to predict endurance performance in cyclists $[29,30]$ and to distinguish elite cyclists from well-trained cyclists [30]. Concurrent endurance and heavy strength training is reported to increase $W_{\max }$ or time to exhaustion at $W_{\max }$ in trained to well-trained cyclists $[1,17,19,24,31]$. Another factor important for the cycling performance in mass start races is the ability to close a gap, break away from the pack, or perform well in the final sprint [32]. The outcome of these crucial moments is largely decided by anaerobic abilities and the size of the involved muscle mass $[33,34]$. Based on the beneficial effects of heavy strength training on muscle strength and muscle mass, it is as expected that concurrent training has been reported to improve the ability to generate a high power output for a short period of time $[1,2,17]$.

\section{Sex Difference in the Effect of Strength Training on Cycling Performance}

Since most studies investigating the effects of strength training on cycling performance include only male cyclists, we performed a study on the effects of strength training on cycling performance and performance determinants in female cyclists [2,15]. The female cyclists in this study performed a strength training program identical to what we previously used to induce beneficial effects on cycling performance in male cyclists $[1,16,17]$. This strength training program lasted for 11-12 weeks with two sessions per week with a training load of 10-4 RM, including four exercises for the lower body with three sets. Both the men and the women continued their normal endurance training. In both male and female cyclists, cycling performance, measured as the average sustainable power output during a 40-min performance test, increased to the same amount after adding strength training to their normal training (men: $6.0 \pm 5.6 \%$, women: $6.4 \pm 7.9 \%$, Figure 1). The improved performance was not because of increased $\mathrm{VO}_{2 \max }$ as strength training did not improve $\mathrm{VO}_{2 \max }$ compared to control cyclists performing their normal endurance training in either the male or female cyclists. Cycling economy measured by the traditional method (i.e., short, 3-5 min, submaximal bouts of cycling) was improved only in the female cyclists in our studies (Figure 1), and the percent change between men and women was significantly different $(p=0.016)$. Therefore, it is possible that female cyclists have a larger potential for improving cycling economy than male cyclists by adding heavy strength training to their normal endurance training. On the other hand, the male cyclists were on a somewhat higher performance level and completed more endurance training than the female cyclists (9.9 h vs. $5.1 \mathrm{~h}$ per week). It appears difficult to improve cycling economy in very well-trained cyclists [3]. In fact, improved cycling economy after heavy strength training has also been reported in male cyclists on a lower performance level $[24,26,27]$. However, research in very well-trained and elite female cyclists is lacking, and it might be that as for men, they do not see an improved cycling economy after strength training, at least when measured during 3-5 min submaximal bouts of cycling. 


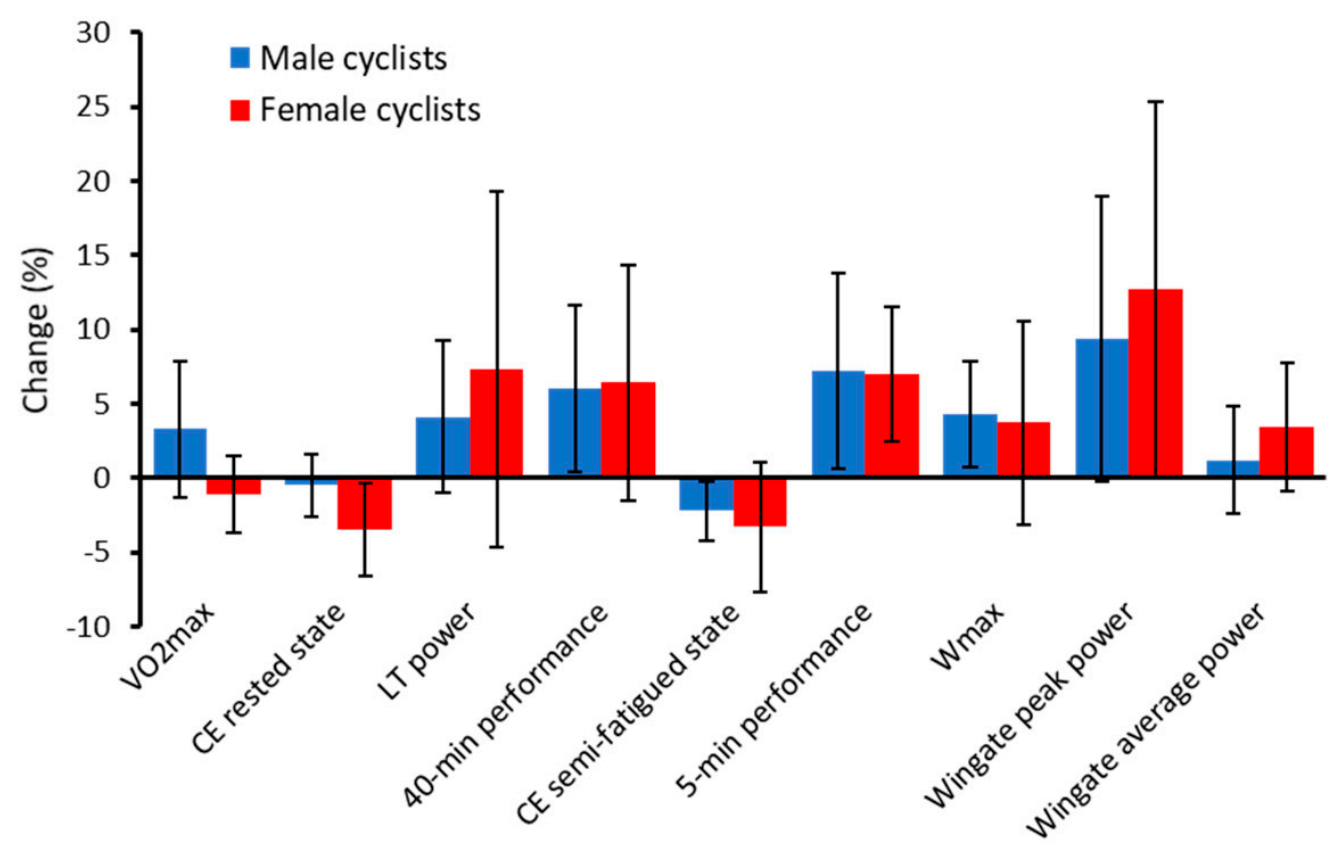

Figure 1. Percent change in physiological measurements and cycling performance after 11-12 weeks of heavy strength training in male and female cyclists. The results from the male cyclists are from $[1,16]$, and the results from the female cyclists are from $[2,15]$. Values are mean $\pm \mathrm{SD}$. $\mathrm{RM}=$ repetition maximum, $\mathrm{CSA}=$ cross sectional area, $\mathrm{VO}_{2 \mathrm{max}}=$ maximal oxygen consumption, $\mathrm{W}_{\max }=$ power output at $\mathrm{VO}_{2 \max }, \mathrm{CE}=$ cycling economy, $\mathrm{LT}=$ lactate threshold. Note: A negative change in cycling economy indicates reduced $\mathrm{VO}_{2}$ and improved cycling economy. CE semi fatigued state was measured during the last hour of a $3 \mathrm{~h}$ submaximal cycling trial, and the 5-min performance was measured directly following the $3 \mathrm{~h}$ trial. The increase in $\mathrm{VO}_{2 \max }$ in the male cyclists was not different from control male cyclists.

We measured $\% \mathrm{VO}_{2 \max }$ with $\mathrm{VO}_{2}$ measurements during the 40-min performance test in the female cyclists and found an improvement from $78.9 \%$ to $82.2 \%$ of $\mathrm{VO}_{2 \max }$. Unfortunately, we did not perform this measurement in the male cyclists; however, the improved 40-min performance in the male cyclists compared to the male control cyclists with similar changes in $\mathrm{VO}_{2 \max }$ and cycling economy indicate an improved $\% \mathrm{VO}_{2 \max }$. Similar findings have also been reported in other elite male cyclists [3]. This study found an $8 \%$ increase in the average power output during a 45 -min performance test with no changes in cycling economy and $\mathrm{VO}_{2 \max }$ after young elite cyclists added strength training. The authors calculated that the average power output during the 45-min test increased from $76 \%$ to $83 \%$ of the power output corresponding to $100 \%$ of $\mathrm{VO}_{2 \max }$ after the strength training intervention. Therefore, it appears that both male and female cyclists improve $\% \mathrm{VO}_{2 \max }$ after a period of heavy strength training. It might be speculated that the male cyclists increased their $\% \mathrm{VO}_{2 \max }$ more than the female cyclists, since the improvement in 40-min performance test was similar despite only the female cyclists improved cycling economy (Figure 1). However, this might also be explained by the increase in $\mathrm{VO}_{2 \max }$ in the male cyclists (similar in both control and strength training group). It is therefore unknown if there are sex differences in the improvement of $\% \mathrm{VO}_{2 \max }$ after concurrent training. The power output at lactate threshold improved similarly in both sexes after strength training (men: $4.1 \pm 5.1 \%$, women: $7.6 \pm 12 \%, p=0.39$, Figure 1 ).

To simulate a typical mass start race in cycling, we performed a test consisting of a $3 \mathrm{~h}$ submaximal cycling trial (at the same absolute power output pre and post) directly followed by a 5-min performance test with the aim of highest possible power output during the 5-min test. The results were similar between the male and female cyclists [15,16]. Both had reduced oxygen consumption and hence improved cycling economy during the last part of the submaximal trial, compared to before the strength training intervention and the control groups. This was accompanied by reduced heart rate in both men and women. This shows that male cyclists on a high level can also improve cycling economy if this is 
tested in a semi-fatigued state. However, again there was an indication of larger potential for improvements in cycling economy after strength training in women than men, as they improved cycling economy during the last two hours of the test, compared to only the last hour in the male cyclists. The improved cycling economy during the last part of this prolonged trial probably led to a lower magnitude of fatigue at the end of the trial, and both the male and female cyclists increased average power output in the following 5-min performance test to the same degree after the strength training program (men: $7.2 \pm 6.6 \%$, women: $7.0 \pm 4.5 \%$, Figure 1). None of these changes were observed in either male or female control cyclists.

In our studies, we observed that strength training increased the ability to generate high power output for a short period of time, measured as peak power output in the Wingate test in both male $(9.4 \pm 9.6 \%)$ and female $(12.7 \pm 12.6 \%)$ cyclists. In both sexes, the effects on the 30 -sec Wingate mean power were substantially smaller, with no significant increase in the male cyclists and only a small increase $(3.4 \pm 4.3 \%)$ in the female cyclists. The $W_{\max }$ also increased similarly in the male $(4.3 \pm 1.1 \%)$ and female $(3.9 \pm 6.7 \%)$ cyclists, although this change was only statistically significant in men.

The results from our studies show similar strength-training-induced improvements in cycling performance and physiological determinants of cycling performance between the sexes. Therefore, both male and female cyclists can incorporate heavy strength training into their training schedule for maximizing performance. However, the data indicates that the potential for improving cycling economy with strength training might be greater in women. Furthermore, caution is warranted since these studies did not compare men and women directly in the same study. However, similar strength training program, test protocols and testing equipment were used alongside a control group.

To the best of our knowledge, only one other study investigating the effect on concurrent training on cycling performance by comparing a concurrent strength and endurance training group to an endurance-training-only group has focused on female cyclists [7]. In this study, well-trained female cyclists added 12 weeks of heavy strength training (parallel squats two times per week) to their normal endurance training but found no beneficial effect on cycling performance in a 1-h time-trial test nor in cycling economy [7]. However, this might be because the strength training program only included one strength training exercise, making the total strength training volume too low for beneficial effects to occur [8].

\section{Mechanisms behind the Effects of Strength Training on Cycling Performance and Sex Differences in These Mechanisms}

The proposed mechanisms responsible for improved cycling performance after strength training are summarized in Figure 2. One frequently proposed mechanism for the improved cycling economy often observed after cyclists add strength training to their normal training is a larger contribution of type I muscle fibers at a certain power output [4]. Type I fibers have been reported to be more efficient than type II fibers [35,36], and although not an universal finding [37], cycling efficiency has been related to proportions of type I fibers in the active muscles [38-40]. When the maximal muscle strength increases, the force levels required to ride at a certain power output is reduced relatively to maximal force. This implies that the type I muscle fibers can account for a larger proportion of a certain absolute power output $[4,19]$, as follows from the size principle of motor unit recruitment [41]. Furthermore, concurrent heavy strength- and endurance training in female athletes has been reported to increase cross sectional area (CSA) of type I muscle fibers [42], and an increase in the force capacity and CSA of type I muscle fibers can theoretically induce a larger contribution to power output by the economical type I muscle fibers and/or postponing the activation of the less economical type II fibers [4]. The latter highlights the importance of increased muscle CSA in order to improve cycling economy through this mechanism. This is supported by the correlation $(\mathrm{r}=-0.54)$ that we reported between change in CSA of the quadriceps muscle and the improved cycling economy after strength training in the female cyclists [2]. 


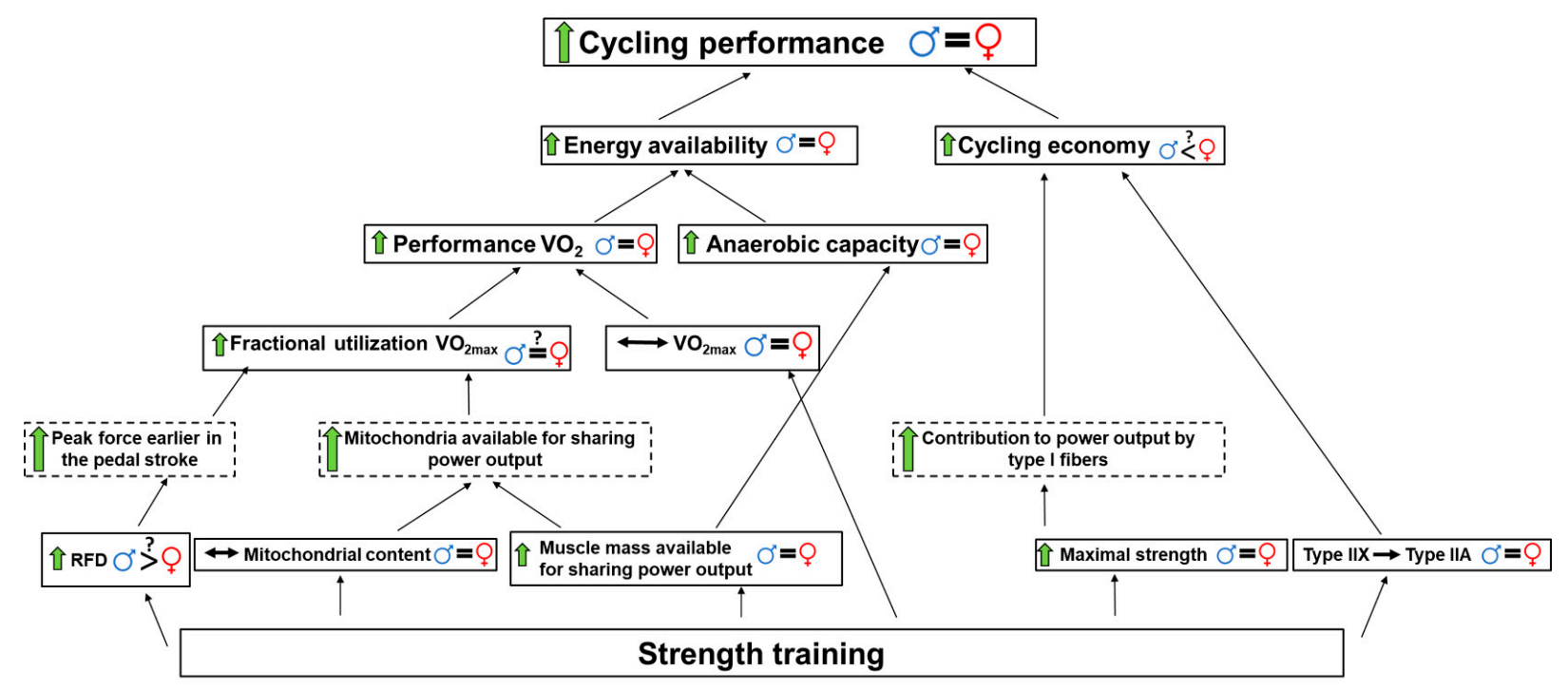

Figure 2. Flow diagram illustrating the proposed mechanisms behind improved cycling performance after strength training in cyclists with possible sex differences indicated with $\odot=$ men and $\&=$ women. Boxes with dashed line indicate theoretical effects of the strength training adaptation. = indicates similar change between sexes, $><$ indicates a larger improvement in one sex, question mark indicates uncertainty, green arrows represent improvement, $\leftrightarrow$ indicates no change, $\mathrm{VO}_{2 \max }=$ maximal oxygen consumption, $\mathrm{RFD}=$ rate of force development.

Another often proposed mechanism is the increase in the proportion of type IIA muscle fibers at the expense of type IIX muscle fibers [2,4]. Some studies have reported that type IIA fibers are more economical than type IIX fibers in vitro [35,36,43,44]. Even though this difference in efficiency between type IIX and type IIA muscle fibers seems to be quite small at physiological temperatures [45], it could in theory improve work economy as well as improve endurance performance due to the larger endurance capacity in type IIA than IIX fibers $[3,43]$. The increases in muscle mass and muscle strength after strength training are reported to be very similar in men and women [46,47]. This is also the case for the transition from type IIX to type IIA after strength training that has been reported to be similar for both sexes in previously untrained subjects [48] and endurance trained athletes [2,3]. However, in our studies we observed a tendency toward a somewhat larger increase in quadriceps muscle CSA (women: $7.4 \pm 5.3 \%$, men: $4.6 \pm 1.7 \%, p=0.11$ ) and lower body muscle strength (women: $38.6 \pm 19.0 \%$, men: $26.0 \pm 6.6 \%, p=0.08$ ) in women than in the men that might explain the improved cycling economy in women and not in the men.

Increased tendon stiffness after strength training in men [49-51] is frequently proposed as an important mechanism behind improved running economy after concurrent training interventions [52-54], due to improved utilization of stored elastic energy and improved muscle contraction mechanics during the running stride. However, it has been observed that female tendons have a lower rate of new connective tissue formation and a lower mechanical strength in response to mechanical loading [55] with a different adaptation in mechanical properties of the tendons after strength training than men [14]. Therefore, it can be speculated that the strength training effect on tendon stiffness is smaller in women than men. However, cycling mainly consists of concentric muscle work $[56,57]$ without a clear stretch-shortening cycle and any potential sex differences in tendon adaptations are likely to have no or only minor impact on cycling economy.

The mechanisms behind increased $\% \mathrm{VO}_{2 \max }$ is unclear. However, it might be related to the increased CSA of the working muscles. The increase in quadriceps CSA in the female cyclists discussed above correlated with changes in the performance $\mathrm{VO}_{2}$ during the 40-min performance test $(\mathrm{r}=0.59)$, which again is decided by $\% \mathrm{VO}_{2 \max }$ and $\mathrm{VO}_{2 \max }[2] . \% \mathrm{VO}_{2 \max }$ is mainly determined by the amount of aerobic enzymes and mitochondria sharing a certain 
workload and $\mathrm{VO}_{2}$ [58-60]. It has been reported that cyclists that are able to spread the power output over a larger amount of their muscle mass has a larger $\% \mathrm{VO}_{2 \max }$ during a 60-min time trial test [61]. Therefore, we have previously suggested that one possible explanation behind improved $\% \mathrm{VO}_{2 \max }$ after strength training can be that increased muscle CSA leads to more muscle mass being available to share a certain power output. Since most longitudinal training studies report unchanged content or activity of aerobic enzyme in previously untrained individuals after strength training [62-64], the total amount aerobic enzymes (mitochondria) available for sharing the workload should be increased [2]. In the female cyclists, we reported no change in the concentration of aerobic enzymes despite an increase in muscle fiber CSA and total quadriceps muscle CSA giving support for this mechanism [2,42].

A frequently proposed mechanism for improved endurance performance after heavy strength training is an increase in rate of force development (RFD) $[3,24,65]$. Increased RFD may reduce the time to reach the force needed to sustain a certain power output and may thus allow for a prolonged relaxation phase in each pedal stroke, and consequently facilitate better blood flow to exercising muscles [3,4]. If increased RFD improves performance, thereby allowing cycling at a higher mean power output, this will increase oxygen demand and therefore also performance $\mathrm{VO}_{2}$. If $\mathrm{VO}_{2 \max }$ remains unchanged, this will lead to increased $\% \mathrm{VO}_{2 \max }$. Even though concurrent strength and endurance training can reduce the improvement in RFD compared to strength training alone [66,67], increased RFD and earlier peak force during the pedal stroke are likely contributors to improved $\% \mathrm{VO}_{2 \max }$ after strength training. A study from our group demonstrated that elite cyclists exhibited earlier peak torque in the pedal stroke following a strength training program like the one used in our other studies discussed above. Furthermore, this earlier peak torque correlated $(\mathrm{r}=-0.63)$ with a concomitant improvement in mean power output during a 40-min performance test [17]. As the intended movement velocity is important for changes in RFD when training with high loads [68] cyclists should perform strength training with maximal intended movement velocity for maximizing improvements in RFD.

As most studies report similar relative improvements in muscle mass or muscle CSA between men and women, any increase in $\% \mathrm{VO}_{2 \max }$ through an increased muscle mass available for sharing a certain power output should be similar between the sexes. Changes in RFD in absolute values after strength training are mainly because of increased maximal strength, increased muscle mass, and changes in rapid activation of the muscles, and these adaptations are similar between sexes [47]. Increased stiffness of tendons might theoretically also contribute to increased RFD as stiffer tendons will transfer the force from the muscles to the bones faster [47]. Therefore, it might be speculated that men would have larger increase in RFD since they appear to have larger increase in tendon stiffness. A recent meta-analysis indicated that men increase RFD to a larger degree than women after strength training, but these results were unclear because of shortage of data from female subjects [68]. Therefore, the adaptations to strength training that probably lead to improved $\% \mathrm{VO}_{2 \max }$ in cyclists seem to mostly be similar for men and women, further supporting that strength training will improve $\% \mathrm{VO}_{2 \max }$ in both men and women. However, future studies should further investigate if there might be sex differences in the magnitude of this improvement.

As rationalized, a small increase in CSA in the main locomotor muscle seems to be an important factor, both for the improvement in cycling economy and $\% \mathrm{VO}_{2 \max }$ and hence cycling performance after strength training. In our study with the female cyclists, the increase in muscle CSA correlated with both improved cycling economy $(r=-0.54)$, improved performance $\mathrm{VO}_{2}(\mathrm{r}=0.59)$, and improved 40-min performance $(\mathrm{r}=0.73)$ [2]. Furthermore, increased muscle CSA is also important for the ability to generate high power output for a short period and anaerobic abilities [33,34]. Based on these findings, female and male cyclists that add strength training to their normal training should aim for increased muscle CSA in the important muscles for power output when cycling. This contrasts with popular belief among cyclists and coaches, who usually try to avoid increased muscle 
CSA in fear of negative consequences of increased body mass. However, it is important to remember that a small increase in muscle CSA in the main locomotor musculature does not have large impact on total body mass. In fact, in our studies we do not report increased body mass despite significant increases in quadriceps muscle CSA, and performance is also improved when adjusted for body mass in both female [2] and male cyclists [1]. Furthermore, the increased muscle CSA does not impair capillary density in either female or male cyclists [2,3]. Based on the limited available literature in female cyclists, it is difficult to say if the optimal strength training program to improve cycling performance should be different between male and female cyclists. In our studies, the strength training program was identical and produced a similar improvement in performance. There is also limited evidence indicating that the mechanisms behind improved performance are different. Therefore, there are no indications that male and female cyclists should use different strength training programs, but this should be explored in future studies.

\section{Summary}

Our review of the literature, which focuses on our own studies using similar strength training and test measurements in male and female cyclists, shows that both sexes improve cycling performance and therefore can add heavy strength training to their normal training in order to improve performance. The improved performance seems to be because of both improved cycling economy and $\% \mathrm{VO}_{2 \max }$. Both moderately trained male and female cyclists have been reported to improve cycling economy after heavy strength training. However, it seems to be difficult to improve cycling economy after concurrent training in very well-trained and elite male cyclists, indicating that improvement in cycling economy is easier in women. However, studies including elite female cyclists are lacking, and there are indices of improved cycling economy even in well-trained male cyclists when tested after prolonged cycling in semi-fatigued state. The improved $\% \mathrm{VO}_{2 \max }$ seems to be similar between male and female cyclists after concurrent training. However, future studies should include direct measurements of $\% \mathrm{VO}_{2}$ max with sufficient numbers of both male and female cyclists with similar training background that in parallel carries out the same strength training program to directly compare the effects between sexes and further explore if there might be differences. The physiological adaptations after strength training believed to be responsible for these improvements seem mostly similar between sexes. Improvements in the ability to generate high power output for a short period of time and anaerobic abilities after strength training also seem to be similar between male and female cyclists.

Author Contributions: The first draft of the manuscript was written in collaboration by O.V. and B.R.R. Both authors commented on previous versions of the manuscript. Both authors have read and agreed to the published version of the manuscript.

Funding: This research received no external funding.

Institutional Review Board Statement: Not applicable.

Informed Consent Statement: Not applicable.

Data Availability Statement: Not applicable.

Conflicts of Interest: The authors declare no conflict of interest.

\section{References}

1. Rønnestad, B.R.; Hansen, E.A.; Raastad, T. Effect of heavy strength training on thigh muscle cross-sectional area, performance determinants, and performance in well-trained cyclists. Eur. J. Appl. Physiol. 2010, 108, 965-975. [CrossRef] [PubMed]

2. Vikmoen, O.; Ellefsen, S.; Trøen, Ø.; Hollan, I.; Hanestadhaugen, M.; Raastad, T.; Rønnestad, B.R. Strength training improves cycling performance, fractional utilization of $\mathrm{VO}_{2 \max }$ and cycling economy in female cyclists. Scand. J. Med. Sci. Sports 2016, 26, 384-396. [CrossRef] [PubMed]

3. Aagaard, P.; Andersen, J.L.; Bennekou, M.; Larsson, B.; Olesen, J.L.; Crameri, R.; Magnusson, S.P.; Kjaer, M. Effects of resistance training on endurance capacity and muscle fiber composition in young top-level cyclists. Scand. J. Med. Sci. Sports 2011, 21, e298-e307. [CrossRef] 
4. Rønnestad, B.R.; Mujika, I. Optimizing strength training for running and cycling endurance performance: A review. Scand. J. Med. Sci. Sports 2014, 24, 603-612. [CrossRef] [PubMed]

5. Beattie, K.; Kenny, I.C.; Lyons, M.; Carson, B.P. The Effect of Strength Training on Performance in Endurance Athletes. Sports Med. 2014, 44, 845-865. [CrossRef] [PubMed]

6. $\quad$ Berryman, N.; Mujika, I.; Arvisais, D.; Roubeix, M.; Binet, C.; Bosquet, L. Strength Training for Middle- and Long-Distance Performance: A Meta-Analysis. Int. J. Sports Physiol. Perform. 2018, 13, 57-63. [CrossRef]

7. Bishop, D.; Jenkins, D.G.; Mackinnon, L.T.; McEniery, M.; Carey, M.F. The effects of strength training on endurance performance and muscle characteristics. Med. Sci. Sports Exerc. 1999, 31, 886-891. [CrossRef] [PubMed]

8. Mujika, I.; Rønnestad, B.R.; Martin, D.T. Effects of Increased Muscle Strength and Muscle Mass on Endurance-Cycling Performance. Int. J. Sports Physiol. Perform. 2016, 11, 283-289. [CrossRef]

9. Montalvo-Pérez, A.; Alejo, L.B.; Valenzuela, P.L.; Gil-Cabrera, J.; Talavera, E.; Luia, A.; Barranco-Gil, D. Traditional Versus Velocity-Based Resistance Training in Competitive Female Cyclists: A Randomized Controlled Trial. Front. Physiol. 2021, 12. [CrossRef]

10. Hunter, S.K. Sex differences in human fatigability: Mechanisms and insight to physiological responses. Acta Physiol. 2014, 210, 768-789. [CrossRef]

11. Tarnopolsky, M.A. Gender Differences in Substrate Metabolism during Endurance Exercise. Can. J. Appl. Physiol. 2000, 25, 312-327. [CrossRef] [PubMed]

12. Kraemer, W.J.; Ratamess, N.A. Hormonal Responses and Adaptations to Resistance Exercise and Training. Sports Med. 2005, 35, 339-361. [CrossRef] [PubMed]

13. Vingren, J.L.; Kraemer, W.J.; Hatfield, D.L.; Volek, J.S.; Ratamess, N.A.; Anderson, J.M.; Häkkinen, K.; Ahtiainen, J.; Fragala, M.S.; Thomas, G.A.; et al. Effect of resistance exercise on muscle steroid receptor protein content in strength-trained men and women. Steroids 2009, 74, 1033-1039. [CrossRef]

14. McMahon, G.; Morse, C.I.; Winwood, K.; Burden, A.; Onambélé, G.L. Gender associated muscle-tendon adaptations to resistance training. PLoS ONE 2018, 13, e0197852. [CrossRef]

15. Vikmoen, O.; Rønnestad, B.R.; Ellefsen, S.; Raastad, T. Heavy strength training improves running and cycling performance following prolonged submaximal work in well-trained female athletes. Physiol. Rep. 2017, 5, e13149. [CrossRef]

16. Rønnestad, B.R.; Hansen, E.A.; Raastad, T. Strength training improves 5-min all-out performance following $185 \mathrm{~min}$ of cycling. Scand. J. Med. Sci. Sports 2011, 21, 250-259. [CrossRef]

17. Rønnestad, B.R.; Hansen, J.; Hollan, I.; Ellefsen, S. Strength training improves performance and pedaling characteristics in elite cyclists. Scand. J. Med. Sci. Sports 2015, 25, e89-e98. [CrossRef]

18. Joyner, M.J.; Coyle, E.F. Endurance exercise performance: The physiology of champions. J. Physiol. 2008, 586, 35-44. [CrossRef] [PubMed]

19. Hickson, R.C.; Dvorak, B.A.; Gorostiaga, E.M.; Kurowski, T.T.; Foster, C. Potential for strength and endurance training to amplify endurance performance. J. Appl. Physiol. 1988, 65, 2285-2290. [CrossRef]

20. Koninckx, E.; Van Leemputte, M.; Hespel, P. Effect of isokinetic cycling versus weight training on maximal power output and endurance performance in cycling. Eur. J. Appl. Physiol. 2010, 109, 699-708. [CrossRef]

21. Bastiaans, J.J.; Van Diemen, A.B.; Veneberg, T.; Jeukendrup, A.E. The effects of replacing a portion of endurance training by explosive strength training on performance in trained cyclists. Eur. J. Appl. Physiol. 2001, 86, 79-84. [CrossRef]

22. Levin, G.T.; Mcguigan, M.R.; Laursen, P.B. Effect of Concurrent Resistance and Endurance Training on Physiologic and Performance Parameters of Well-Trained Endurance Cyclists. J. Strength Cond. Res. 2009, 23, 2280-2286. [CrossRef]

23. Psilander, N.; Frank, P.; Flockhart, M.; Sahlin, K. Adding strength to endurance training does not enhance aerobic capacity in cyclists. Scand. J. Med. Sci. Sports 2014, 25, e353-e359. [CrossRef] [PubMed]

24. Sunde, A.; Støren, Ø.; Bjerkaas, M.; Larsen, M.H.; Hoff, J.; Helgerud, J. Maximal Strength Training Improves Cycling Economy in Competitive Cyclists. J. Strength Cond. Res. 2010, 24, 2157-2165. [CrossRef]

25. Rønnestad, B.R.; Hansen, E.A.; Raastad, T. In-season strength maintenance training increases well-trained cyclists' performance. Eur. J. Appl. Physiol. 2010, 110, 1269-1282. [CrossRef] [PubMed]

26. Barrett-O'Keefe, Z.; Helgerud, J.; Wagner, P.D.; Richardson, R.S. Maximal strength training and increased work efficiency: Contribution from the trained muscle bed. J. Appl. Physiol. 2012, 113, 1846-1851. [CrossRef] [PubMed]

27. Louis, J.; Hausswirth, C.; Easthope, C.; Brisswalter, J. Strength training improves cycling efficiency in master endurance athletes. Eur. J. Appl. Physiol. 2012, 112, 631-640. [CrossRef]

28. Jones, A.M.; Carter, H. The Effect of Endurance Training on Parameters of Aerobic Fitness. Sports Med. 2000, $29,373-386$. [CrossRef] [PubMed]

29. Hawley, J.A.; Noakes, T.D. Peak power output predicts maximal oxygen uptake and performance time in trained cyclists. Eur. J. Appl. Physiol. 1992, 65, 79-83. [CrossRef]

30. Lucía, A.; Pardo, J.; Durántez, A.; Hoyos, J.; Chicharro, J.L. Physiological differences between professional and elite road cyclists. Int. J. Sports Med. 1998, 19, 342-348. [CrossRef] [PubMed]

31. Beattie, K.; Carson, B.P.; Lyons, M.; Kenny, I.C. The Effect of Maximal- and Explosive-Strength Training on Performance Indicators in Cyclists. Int. J. Sports Physiol. Perform. 2017, 12, 470-480. [CrossRef] [PubMed] 
32. Atkinson, G.; Davison, R.; Jeukendrup, A.; Passfield, L. Science and cycling: Current knowledge and future directions for research. J. Sports Sci. 2003, 21, 767-787. [CrossRef]

33. Izquierdo, M.; Ibáñez, J.; Häkkinen, K.; Kraemer, W.J.; Ruesta, M.; Gorostiaga, E.M. Maximal strength and power, muscle mass, endurance and serum hormones in weightlifters and road cyclists. J. Sports Sci. 2004, 22, 465-478. [CrossRef] [PubMed]

34. Lee, H.J.; Lee, K.W.; Lee, Y.W.; Kim, H.J. Correlation between Cycling Power and Muscle Thickness in Cyclists. Clin. Anat. 2018, 31, 899-906. [CrossRef] [PubMed]

35. Barclay, C.J.; Constable, J.K.; Gibbs, C.L. Energetics of fast- and slow-twitch muscles of the mouse. J. Physiol. 1993, 472, 61-80. [CrossRef] [PubMed]

36. Smith, N.P.; Barclay, C.J.; Loiselle, D.S. The efficiency of muscle contraction. Prog. Biophys. Mol. Biol. 2005, 88, 1-58. [CrossRef] [PubMed]

37. Hopker, J.G.; Coleman, D.A.; Gregson, H.C.; Jobson, S.A.; Von Der Haar, T.; Wiles, J.; Passfield, L. The influence of training status, age, and muscle fiber type on cycling efficiency and endurance performance. J. Appl. Physiol. 2013, 115, 723-729. [CrossRef]

38. Coyle, E.F.; Sidossis, L.S.; Horowitz, J.F.; Beltz, J.D. Cycling efficiency is related to the percentage of type I muscle fibers. Med. Sci. Sports Exerc. 1992, 24, 782-788. [CrossRef] [PubMed]

39. Horowitz, J.F.; Sidossis, L.S.; Coyle, E.F. High Efficiency of Type I Muscle Fibers Improves Performance. Int. J. Sports Med. 1994, 15, 152-157. [CrossRef]

40. Mogensen, M.; Bagger, M.; Pedersen, P.K.; Fernström, M.; Sahlin, K. Cycling efficiency in humans is related to low UCP3 content and to type I fibres but not to mitochondrial efficiency. J. Physiol. 2006, 571, 669-681. [CrossRef]

41. Henneman, E.; Somjen, G.; Carpenter, D.O. Functional Significance of Cell Size in Spinal Motoneurons. J. Neurophysiol. 1965, 28, 560-580. [CrossRef] [PubMed]

42. Vikmoen, O.; Raastad, T.; Seynnes, O.; Bergstrøm, K.; Ellefsen, S.; Rønnestad, B.R. Effects of Heavy Strength Training on Running Performance and Determinants of Running Performance in Female Endurance Athletes. PLoS ONE 2016, 11, e0150799. [CrossRef] [PubMed]

43. Bottinelli, R.; Pellegrino, M.; Canepari, M.; Rossi, R.; Reggiani, C. Specific contributions of various muscle fibre types to human muscle performance: An in vitro study. J. Electromyogr. Kinesiol. 1999, 9, 87-95. [CrossRef]

44. Westerblad, H.; Bruton, J.D.; Katz, A. Skeletal muscle: Energy metabolism, fiber types, fatigue and adaptability. Exp. Cell Res. 2010, 316, 3093-3099. [CrossRef] [PubMed]

45. Lionikas, A.; Li, M.; Larsson, L. Human skeletal muscle myosin function at physiological and non-physiological temperatures. Acta Physiol. 2006, 186, 151-158. [CrossRef]

46. Abe, T.; DeHoyos, D.V.; Pollock, M.L.; Garzarella, L. Time course for strength and muscle thickness changes following upper and lower body resistance training in men and women. Eur. J. Appl. Physiol. 2000, 81, 174-180. [CrossRef]

47. Folland, J.P.; Williams, A.G. The adaptations to strength training: Morphological and neurological contributions to increased strength. Sports Med. 2007, 37, 145-168. [CrossRef]

48. Staron, R.S.; Karapondo, D.L.; Kraemer, W.J.; Fry, A.C.; Gordon, S.E.; Falkel, J.E.; Hagerman, F.C.; Hikida, R.S. Skeletal muscle adaptations during early phase of heavy-resistance training in men and women. J. Appl. Physiol. 1994, 76, 1247-1255. [CrossRef]

49. Kongsgaard, M.; Reitelseder, S.; Pedersen, T.G.; Holm, L.; Aagaard, P.; Kjaer, M.; Magnusson, S.P. Region specific patellar tendon hypertrophy in humans following resistance training. Acta Physiol. 2007, 191, 111-121. [CrossRef]

50. Kubo, K.; Kanehisa, H.; Ito, M.; Fukunaga, T. Effects of isometric training on the elasticity of human tendon structures in vivo. J. Appl. Physiol. 2001, 91, 26-32. [CrossRef]

51. Reeves, N.D.; Maganaris, C.N.; Narici, M.V. Effect of strength training on human patella tendon mechanical properties of older individuals. J. Physiol. 2003, 548, 971-981. [CrossRef]

52. Albracht, K.; Arampatzis, A. Exercise-induced changes in triceps surae tendon stiffness and muscle strength affect running economy in humans. Eur. J. Appl. Physiol. 2013, 113, 1605-1615. [CrossRef] [PubMed]

53. Guglielmo, L.; Greco, C.; Denadai, B.S. Effects of Strength Training on Running Economy. Int. J. Sports Med. 2008, 30, 27-32. [CrossRef] [PubMed]

54. Saunders, P.U.; Telford, R.D.; Pyne, D.B.; Peltola, E.M.; Cunningham, R.B.; Gore, C.J.; Hawley, J.A. Short-Term Plyometric Training Improves Running Economy in Highly Trained Middle and Long Distance Runners. J. Strength Cond. Res. 2006, 20, 947-954. [CrossRef] [PubMed]

55. Magnusson, S.P.; Hansen, M.; Langberg, H.; Miller, B.; Haraldsson, B.; Westh, E.K.; Koskinen, S.; Aagaard, P.; Kjaer, M. The adaptability of tendon to loading differs in men and women. Int. J. Exp. Pathol. 2007, 88, 237-240. [CrossRef]

56. Bijker, K.E.; De Groot, G.; Hollander, A.P. Differences in leg muscle activity during running and cycling in humans. Eur. J. Appl. Physiol. 2002, 87, 556-561. [CrossRef]

57. Ericson, M.O.; Nisell, R.; Arborelius, U.P.; Ekholm, J. Muscular activity during ergometer cycling. Scand. J. Rehabil. Med. 1985, 17, 53-61. [PubMed]

58. Coyle, E.F. Integration of the physiological factors determining endurance performance ability. Exerc. Sport Sci. Rev. 1995, 23, 25-63. [CrossRef]

59. Holloszy, J.O.; Coyle, E.F. Adaptations of skeletal muscle to endurance exercise and their metabolic consequences. J. Appl. Physiol. 1984, 56, 831-838. [CrossRef] [PubMed] 
60. Ivy, J.L.; Withers, R.T.; Van Handel, P.J.; Elger, D.H.; Costill, D.L. Muscle respiratory capacity and fiber type as determinants of the lactate threshold. J. Appl. Physiol. 1980, 48, 523-527. [CrossRef]

61. Coyle, E.F.; Feltner, M.E.; Kautz, S.A.; Hamilton, M.T.; Montain, S.J.; Baylor, A.M.; Abraham, L.D.; Petrek, G.W. Physiological and biomechanical factors associated with elite endurance cycling performance. Med. Sci. Sports Exerc. 1991, $23,93-107$. [CrossRef] [PubMed]

62. Alvehus, M.; Boman, N.; Söderlund, K.; Svensson, M.B.; Burén, J. Metabolic adaptations in skeletal muscle, adipose tissue, and whole-body oxidative capacity in response to resistance training. Eur. J. Appl. Physiol. 2014, 114, 1463-1471. [CrossRef] [PubMed]

63. Bell, G.J.; Syrotuik, D.; Martin, T.P.; Burnham, R.; Quinney, H.A. Effect of concurrent strength and endurance training on skeletal muscle properties and hormone concentrations in humans. Eur. J. Appl. Physiol. 2000, 81, 418-427. [CrossRef]

64. Green, H.; Goreham, C.; Ouyang, J.; Ball-Burnett, M.; Ranney, D. Regulation of fiber size, oxidative potential, and capillarization in human muscle by resistance exercise. Am. J. Physiol. Integr. Comp. Physiol. 1999, 276, R591-R596. [CrossRef] [PubMed]

65. Hoff, J.; Helgerud, J.; Wisløff, U. Maximal strength training improves work economy in trained female cross-country skiers. Med. Sci. Sports Exerc. 1999, 31, 870-877. [CrossRef]

66. Tsitkanou, S.; Spengos, K.; Stasinaki, A.-N.; Zaras, N.; Bogdanis, G.; Papadimas, G.; Terzis, G. Effects of high-intensity interval cycling performed after resistance training on muscle strength and hypertrophy. Scand. J. Med. Sci. Sports 2016, 27, 1317-1327. [CrossRef]

67. Spiliopoulou, P.; Zaras, N.; Methenitis, S.; Papadimas, G.; Papadopoulos, C.; Bogdanis, G.C.; Terzis, G. Effect of Concurrent Power Training and High-Intensity Interval Cycling on Muscle Morphology and Performance. J. Strength Cond. Res. 2019. [CrossRef]

68. Blazevich, A.J.; Wilson, C.J.; Alcaraz, P.E.; Rubio-Arias, J.A. Effects of Resistance Training Movement Pattern and Velocity on Isometric Muscular Rate of Force Development: A Systematic Review with Meta-analysis and Meta-regression. Sports Med. 2020, 50, 943-963. [CrossRef] 